\title{
Involvement of reactive oxygen species and JNK in increased expression of MCP-1 and infiltration of inflammatory cells in pressure-overloaded rat hearts
}

\author{
FUJUN SHANG $^{1}$, JIEPIN WANG ${ }^{2}$, XIONGTAO LIU ${ }^{1}$, JUN LI $^{1}$, QIANGSUN ZHENG ${ }^{1}$, \\ YUSHENG XUE $^{1}$ and LIANYOU ZHAO ${ }^{1}$
}

Departments of ${ }^{1}$ Cardiology, and ${ }^{2}$ Pharmacy, Tangdu Hospital,

The Fourth Military Medical University, Xi'an 710038, P.R. China

Received December 2, 2011; Accepted March 22, 2012

DOI: $10.3892 / \mathrm{mmr} .2012 .852$

\begin{abstract}
Increasing evidence has shown that inflammation is involved in pressure overload-induced cardiac remodeling. Monocyte chemoattractant protein-1 (MCP-1) plays a pivotal role in the inflammatory process. However, the mechanisms underlying the upregulation of MCP-1 expression remain poorly understood. In the present study, we examined the hypothesis that an increased production of reactive oxygen species (ROS) mediates the upregulation of MCP-1. In a pressure-overloaded rat heart model with abdominal aortic coarctation (AC), superoxide dismutase-inhibitable cytochrome $\mathrm{C}$ reduction assay showed that ROS generation in the myocardium increased significantly at 1 week by $61 \%(n=8, P<0.01)$, peaked at 2 weeks and maintained these high levels for 4 weeks. The elevation of ROS was paralleled by the increased expression of MCP-1 and left ventricular remodeling (cardiac hypertrophy, perivascular and interstitial fibrosis). The oral administration of the antioxidant, $\mathrm{N}$-acetylcysteine (NAC, $0.2 \mathrm{~g} / \mathrm{kg} / \mathrm{day}$ ), for 2 or 4 weeks, significantly attenuated ROS production by 69 and $68 \%$, respectively ( $n=8, P<0.01)$, as well as left ventricular remodeling. NAC treatment for 2 weeks also significantly reduced the MCP-1 mRNA and protein levels by 52 and $60 \%$, respectively $(\mathrm{n}=4-8$, both $\mathrm{P}<0.01)$, but had no effect on blood pressure. In the rats with $\mathrm{AC}$ at 2 weeks, when MCP-1 expression and inflammation changes were overt, immunoblotting with phospho-specific antibodies revealed that extracellular regulated kinase (ERK) and c-Jun $\mathrm{NH}_{2}$-terminal kinase (JNK), but not p38 mitogen-activated protein kinase, were activated. NAC administration attenuated JNK activation, but had no effect on ERK. Our results suggest that increased ROS production may
\end{abstract}

Correspondence to: Dr Jiepin Wang or Professor Lianyou Zhao, Department of Cardiology, Tangdu Hospital, The Fourth Military Medical University, 1 Xinsi Road, Baqiao District, Xi'an 710038, P.R. China

E-mail: wangjp@fmmu.edu.cn

E-mail: zhly717642@hotmail.com

Key words: reactive oxygen species, hypertension, pressure overloadinduced cardiac remodeling, monocyte chemoattractant protein-1 play an important role in the increased expression of MCP-1 in pressure overload-induced cardiac remodeling. JNK is likely involved in the signaling pathway.

\section{Introduction}

Cardiac remodeling is an independent risk factor for cardiovascular events in the context of hypertension and other cardiovascular diseases. Myocardial hypertrophy and matrix fibrosis are important hallmarks of cardiac remodeling (1). Increasing evidence has shown that inflammation is implicated in the development of cardiac hypertrophy and fibrosis associated with hypertension (2). The infiltration of inflammatory cells, particularly monocytes and macrophages, into the cardiac interstitium is the key step in the initiation of inflammatory reaction, and chemokines have been found to play a pivotal role in the migration of inflammatory cells. Monocyte chemoattractant protein-1 (MCP-1) is a potent chemoattractant for monocytes (3). It has been demonstrated that the expression of MCP-1 is significantly increased in hypertrophic cardiac tissues and is involved in cardiac remodeling in various hypertensive models induced nitric oxide synthase or pressure overload. The blockage of MCP-1 with specific neutralizing antibody has been shown to attenuate cardiac hypertrophy and fibrosis $(4,5)$. However, the molecular mechanisms underlying the upregulation of MCP-1 in hypertrophic cardiac tissues remain poorly understood.

Reactive oxygen species (ROS), in addition to their detrimental effects on cells when produced in large amounts, have been recognized as important cellular signaling molecules, and are involved in many physiological and pathological processes (6). A growing body of evidence has shown that ROS play multiple roles in the initiation and development of hypertension, including the regulation of cell growth and apoptosis, modulation of the extracellular matrix, inactivation of nitric oxide and activation of various protein kinases (7). The increased production of ROS in hypertrophic cardiac tissues has been reported in hypertensive rats and antioxidant intervention has been shown to attenuate the development of pressure overload-induced cardiac hypertrophy $(8,9)$. ROS are known to be able to modulate the transcription of many important genes, mainly via the activation of mitogen-activated 
protein kinases (MAPKs) and other important redox-sensitive signaling molecules (10). The upregulated gene transcription of MCP-1 has been found to be mediated by ROS in cultured vascular endothelial cells (11).

Based on this background information, we hypothesized that the increased production of ROS mediates the upregulation of MCP-1, and the subsequent inflammatory cell infiltration in hypertrophic cardiac tissues. Our results suggest that increased ROS production may play an important role in the increased expression of MCP-1 in pressure-overload induced cardiac remodeling, and that $\mathrm{c}$-Jun $\mathrm{NH}_{2}$-terminal kinase (JNK) is likely involved in the signaling pathway.

\section{Materials and methods}

The experimental protocols were approved by the Animal Care and Use Committee at the Fourth Military Medical University (Xi'an, China) and conformed to the guiding principles of the 'Guide for the Care and Use of Laboratory Animals' published by the USA National Research Council in 1996.

Animal models and experimental protocol. Male SpragueDawley rats (280-320 g) were obtained from the Laboratory Animal Center of the Fourth Military Medical University. After an acclimatization period of at least 1 week, rats were randomly assigned to 3 experimental groups: sham-operated (sham), aortic coarctation (AC), and $\mathrm{AC}$ with $\mathrm{N}$-acetylcysteine (NAC) treatment $(\mathrm{AC}+\mathrm{NAC})$ groups. The $\mathrm{AC}$ and $\mathrm{AC}+\mathrm{NAC}$ group rats were subjected to abdominal $\mathrm{AC}$ procedures as described previously (12). Briefly, rats were anesthetized with sodium pentobarbital $[45 \mathrm{mg} / \mathrm{kg}$, intraperitonealy (i.p.)]. Abdominal AC was performed by ligation of the abdominal aorta between the renal arteries around a blunt 22 -gauge needle with 6-0 silk suture via midline laparotomy. The sham-operated rats underwent a similar procedure without ligation of the abdominal aorta. $\mathrm{AC}$ $+\mathrm{NAC}$ rats were treated with NAC $(0.2 \mathrm{~g} / \mathrm{kg} / \mathrm{d}$, by intragastric administration) initiated after AC. The sham-operated and $\mathrm{AC}$ groups were further divided into subgroups of 1,2,3 and 4 weeks; the AC + NAC group was divided into subgroups of 2 and 4 weeks. Each subgroup consisted of 8 rats. At the end of each time-point, the right carotid artery was cannulated in the anesthetized (sodium pentobarbital, $45 \mathrm{mg} / \mathrm{kg}$, i.p.) rats with a fluid-filled polyethylene catheter connected to a pressure transducer in conjunction with a Grass polygraph (model 79D; Grass Instrument, Quincy, MA, USA). Arterial pressure was recorded when it was stable. Once the blood pressure measurements were taken, the animals were sacrificed by cervical transaction. The thoracic cavity was opened, and the heart was removed and rinsed. The entire left ventricle (LV) was dissected from the heart and weighed. The LV was cut into aliquots; some were fixed in $4 \%$ paraformaldehyde and others snap-frozen in liquid nitrogen, and then stored at $-80^{\circ} \mathrm{C}$ for further analysis.

Histopathology and immunohistochemistry analysis. After fixation (as described above), tissue aliquots were embedded in paraffin and sectioned at 5- $\mu \mathrm{m}$ thickness. Sections were mounted on glass slides. Some samples were stained with picrosirius red solution for collagen, as previously described (13). To determine the degree of collagen fiber accumulation, we randomly selected 5 fields and calculated the ratio of the fibrotic area to the total myocardial area, expressed as the collagen volume fraction, with National Institutes of Health (NIH) Image software (Atlanta, GA, USA). The ratio of the fibrotic area surrounding the vessel wall to the total vessel area, expressed as the perivascular collagen area, was also calculated randomly in 10 coronary arteries per section. The average percentage was determined for each animal.

Quantification of ROS. The NADPH-dependent superoxide $\left(\mathrm{O}_{2}{ }^{-}\right)$production was measured by superoxide dismutase (SOD)-inhibitable cytochrome $\mathrm{C}$ reduction assay as described previously by Li et al (14). Briefly, LV tissue homogenate diluted in Dulbecco's modified Eagle's medium without phenol red (final concentration, $1 \mathrm{mg} / \mathrm{ml}$ ) was distributed in 96-well plates (final volume, $200 \mu \mathrm{l} /$ well). Cytochrome C (500 $\mu \mathrm{M})$ and NADPH $(100 \mu \mathrm{M})$ were added in the presence or absence of SOD $(200 \mathrm{U} / \mathrm{ml})$ and incubated at room temperature for $30 \mathrm{~min}$. Cytochrome $\mathrm{C}$ reduction was measured by a reading absorbance at $550 \mathrm{~nm}$ with a microplate reader (Bio-Rad, Hercules, CA, USA). Superoxide production was calculated as the portion of total ferricytochrome $\mathrm{C}$ reduction that was inhibitable by SOD and normalized by protein content.

Measurement of MCP-1 mRNA levels. The expression of MCP-1 mRNA was measured by semi-quantitative reverse transcription-polymerase chain reaction (RT-PCR) analysis. Total-RNA was extracted from LV tissue after homogenization in a commercial solution (TRIzol, Gibco, Carlsbad, CA, USA). Complementary DNA was synthesized from $4 \mu \mathrm{g}$ of total-RNA with the AMV reverse transcriptase kit (Promega, USA) according to the manufacturer's instructions. Subsequent PCR amplifications were performed in a volume of $50 \mu 1 \mathrm{PCR}$ buffer containing $5 \mu \mathrm{l}$ of cDNA and 1 unit DNA polymerase (Promega). GAPDH was used as the internal control. The following primer pairs were used: MCP-1: forward, 5'-GCT TCT GGG CCT GTT GTT C-3' and reverse, 5'-GGT GTT GGT GGA GTT CGT G-3' (396 bp); GAPDH: forward, 5'-GTC CAT GCC ATC ACT GCC ACT CA-3' and reverse, 5'-GCC GCC TGC TTC ACC ACC TTC TTG-3' (231 bp). The mixture was heated initially for $5 \mathrm{~min}$ at $94^{\circ} \mathrm{C}$ followed by 35 cycles ( $45 \mathrm{sec}$ at $94^{\circ} \mathrm{C}, 45 \mathrm{sec}$ at $58^{\circ} \mathrm{C}, 1 \mathrm{~min}$ at $72^{\circ} \mathrm{C}$ ). A final extension was performed at $72^{\circ} \mathrm{C}$ for $10 \mathrm{~min}$. The PCR products were run on a $1.2 \%$ agarose gel and the bands were visualized with the S-MultiImager Max system (Bio-Rad) and quantified by image analysis software (Quantity One; Bio-Rad).

Determination of MCP-1 protein levels. LV tissue was homogenized in cold phosphate-buffered saline, which contained $1 \%$ Triton X-100, $5 \mathrm{mM}$ dithiothreitol, $20 \mu \mathrm{g} / \mathrm{ml}$ leupeptin, $10 \mu \mathrm{g} /$ $\mathrm{ml}$ pepstatin, $10 \mu \mathrm{g} / \mathrm{ml}$ aprotinin and $1 \mathrm{mM}$ phenylmethylsulfonyl fluoride. MCP-1 protein content in homogenates was determined by quantitative colorimetric sandwich ELISA using a rat MCP-1 assay kit, according to the manufacturer's instructions (BioSource, San Francisco, CA, USA). The absorbance of standards and samples was determined at $450 \mathrm{~nm}$ with a microplate reader. Results were calculated from the standard curve and were recorded as $\mathrm{pg} / \mathrm{mg}$ protein.

Western blot analysis. MAPK activation was determined by western bolt analysis with polyclone antibodies against 
Table I. Hemodynamic and morphometric changes in the rats with AC and the effects of NAC.

\begin{tabular}{|c|c|c|c|c|c|c|}
\hline $\begin{array}{l}\text { Subgroup } \\
(n=8)\end{array}$ & $\begin{array}{c}\text { MBP } \\
(\mathrm{mmHg})\end{array}$ & $\begin{array}{l}\text { BW } \\
(g)\end{array}$ & $\begin{array}{l}\text { LVW } \\
(\mathrm{g})\end{array}$ & $\begin{array}{c}\text { LVW/BW } \\
\text { (mg/g) }\end{array}$ & $\begin{array}{l}\text { CVF } \\
(\%)\end{array}$ & $\begin{array}{c}\text { PVCA } \\
(\%)\end{array}$ \\
\hline Sham-operated, 1 week & $96 \pm 5$ & $337 \pm 7$ & $0.72 \pm 0.03$ & $2.13 \pm 0.04$ & $0.87 \pm 0.19$ & $6.19 \pm 0.41$ \\
\hline AC, 1 week & $157 \pm 4^{\mathrm{a}}$ & $332 \pm 8$ & $0.74 \pm 0.03$ & $2.21 \pm 0.06$ & $1.06 \pm 0.17$ & $9.02 \pm 0.60^{\mathrm{a}}$ \\
\hline Sham-operated, 2 weeks & $97 \pm 6$ & $356 \pm 6$ & $0.78 \pm 0.03$ & $2.17 \pm 0.07$ & $0.84 \pm 0.13$ & $6.18 \pm 0.35$ \\
\hline AC, 2 weeks & $171 \pm 6^{\mathrm{a}}$ & $351 \pm 9$ & $1.05 \pm 0.04^{\mathrm{a}}$ & $2.98 \pm 0.07^{\mathrm{a}}$ & $3.28 \pm 0.22^{\mathrm{a}}$ & $15.03 \pm 0.88^{\mathrm{a}}$ \\
\hline $\mathrm{AC}+\mathrm{NAC}, 2$ weeks & $169 \pm 5^{\mathrm{a}}$ & $357 \pm 7$ & $0.93 \pm 0.05^{\mathrm{b}}$ & $2.59 \pm 0.10^{\mathrm{b}}$ & $2.33 \pm 0.22^{b}$ & $10.13 \pm 0.67^{b}$ \\
\hline Sham-operated, 3 weeks & $96 \pm 5$ & $379 \pm 7$ & $0.82 \pm 0.03$ & $2.16 \pm 0.05$ & $0.89 \pm 0.10$ & $6.21 \pm 0.51$ \\
\hline AC, 3 week & $179 \pm 7^{\mathrm{a}}$ & $382 \pm 5$ & $1.19 \pm 0.03^{\mathrm{a}}$ & $3.10 \pm 0.04^{\mathrm{a}}$ & $5.38 \pm 0.17^{\mathrm{a}}$ & $20.12 \pm 1.01^{\mathrm{a}}$ \\
\hline Sham-operated, 4 weeks & $96 \pm 6$ & $398 \pm 6$ & $0.90 \pm 0.03$ & $2.24 \pm 0.05$ & $0.88 \pm 0.12$ & $6.27 \pm 0.39$ \\
\hline AC, 4 weeks & $185 \pm 7^{\mathrm{a}}$ & $395 \pm 10$ & $1.29 \pm 0.02^{\mathrm{a}}$ & $3.27 \pm 0.04^{\mathrm{a}}$ & $7.09 \pm 0.33^{\mathrm{a}}$ & $24.99 \pm 0.91^{\mathrm{a}}$ \\
\hline $\mathrm{AC}+\mathrm{NAC}, 4$ weeks & $180 \pm 4^{\mathrm{a}}$ & $405 \pm 13$ & $1.07 \pm 0.06^{\mathrm{b}}$ & $2.64 \pm 0.07^{\mathrm{b}}$ & $3.78 \pm 0.16^{\mathrm{b}}$ & $14.13 \pm 0.76^{b}$ \\
\hline
\end{tabular}

${ }^{\mathrm{a}} \mathrm{P}<0.01$ vs. age-matched sham-operated group; ${ }^{\mathrm{b}} \mathrm{P}<0.01$ vs. age-matched $\mathrm{AC}$ group. MBP, mean blood pressure; BW, body weight; LVW, left ventricle weight; CVF, collagen volume fraction; PVCA, perivascular collagen area; AC, aortic coarctation; NAC, N-acetylcysteine.

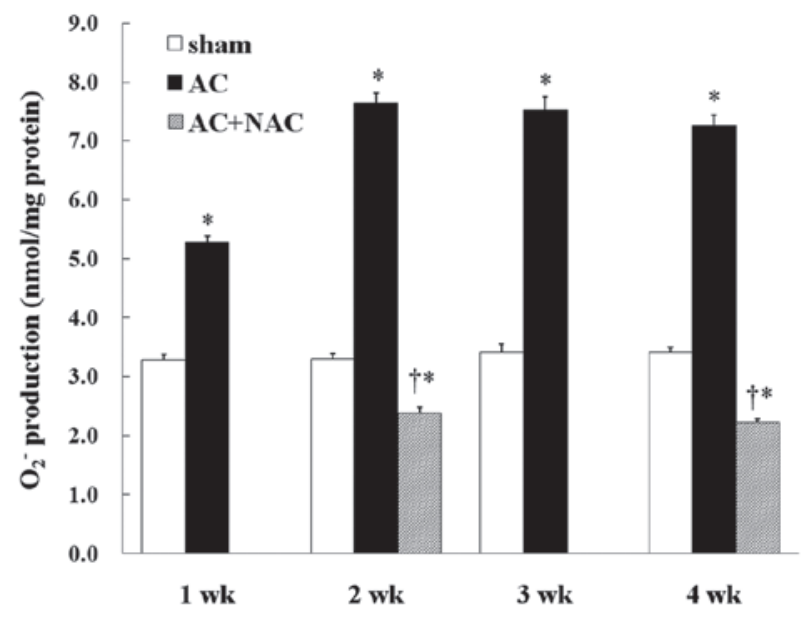

Figure 1. Reactive oxygen species production in the myocardium of pressureoverloaded rat hearts and the effects of NAC administration. ${ }^{*} \mathrm{P}<0.01$ vs. age-matched sham group; ${ }^{\dagger} \mathrm{P}<0.01$ vs. age-matched $\mathrm{AC}$ group, $\mathrm{n}=8$ rats in all the groups. AC, aortic coarctation; NAC, N-acetylcysteine; wk, week.

phosphorylated (phospho)-MAPK isoforms and total-MAPK isoforms (Cell Signaling Technology, Danvers, MA, USA). Protein was extracted from frozen tissue in a cold lysis buffer containing $20 \mathrm{mM}$ Tris (pH 7.5), $0.5 \mathrm{mM}$ EDTA, 0.1\% NP-40, $1 \mathrm{mM} \mathrm{Na} \mathrm{VO}_{4}, 0.5 \%$ sodium deoxycholate, $0.1 \%$ SDS, $1 \mathrm{mM}$ sodium orthovanadate, $0.15 \mathrm{U} / \mathrm{ml}$ aprotinin and $1 \mathrm{mM}$ phenylmethylsulfonyl fluoride. Protein concentration was determined using the Bradford assay (Bio-Rad). After being boiled for $3 \mathrm{~min}$, total protein $(50 \mu \mathrm{g})$ was separated by electrophoresis on a $12 \%$ SDS-polyacrylamide gel and blotted onto a PVDF membrane (Roche, Basel, Switzerland). After blocking in 5\% skim milk, the membranes were incubated with primary antibodies against phospho-extracellular regulated kinase (ERK)1/2 $(1: 2,000)$, phospho-p38 (1/1:1,000) or phospho-JNK1/2 $(1: 1,000)$ overnight. Signals were revealed with chemiluminescence using the ECL-detection system (Amersham Pharmacia Biotech, Piscataway, NJ, USA). The membranes were stripped and reprobed with primary antibodies against the total MAPK isoforms (anti-ERK1/2 diluted to 1:2,000, anti-p38 diluted to 1:1,000, and anti-JNK1/2 diluted to 1:2,000 in TBS buffer). The films were scanned, and the immunoreactive bands were quantified by densitometry with NIH Image software. The MAPK activities were reflected by the ratio of phosphorylation level to the total protein content.

Statistical analysis. All data are expressed as the means \pm SD. Statistical differences between the groups were determined by one-way ANOVA followed by the LSD post-hoc test. $\mathrm{P}<0.05$ denoted a statistically significant difference.

\section{Results}

Effect of AC on ROS production in myocardium and effects of $N A C$ administration. In the sham-operated rats, ROS production measured in LV homogenates did not change significantly after surgery at the different time-points. By contrast, NADPHdependent ROS generation by LV homogenates in the AC group was significantly increased at 1 week after surgery $(5.28 \pm 0.11$ vs. $3.28 \pm 0.11 \mathrm{nM} / \mathrm{mg}$ protein; $\mathrm{P}<0.01)$, peaked at 2 weeks $(7.64 \pm 0.16$ vs. $3.30 \pm 0.09 \mathrm{nM} / \mathrm{mg}$ protein; $\mathrm{P}<0.01)$ and was maintained at high levels for 4 weeks $(7.52 \pm 0.22$ vs. $3.41 \pm 0.14 \mathrm{nM} / \mathrm{mg}$ protein for 3 weeks; $7.25 \pm 0.19$ vs. $3.42 \pm 0.08 \mathrm{nM} / \mathrm{mg}$ protein for 4 weeks; both $\mathrm{P}<0.01)$. In the $\mathrm{AC}+\mathrm{NAC}$ group at 2 and 4 weeks, ROS generation was significantly lower than that of the age-matched AC group $(2.38 \pm 0.09 \mathrm{nM} / \mathrm{mg}$ protein at 2 weeks; $2.22 \pm 0.06 \mathrm{nM} / \mathrm{mg}$ protein at 4 weeks; both $\mathrm{P}<0.01$ ) (Fig. 1). These data suggest that ROS production is upregulated in the pressure-overloaded rat myocardium, and this upregulated ROS production can be blocked by NAC treatment.

Arterial blood pressure and LV morphological changes in rats with $A C$ and effects of NAC administration. Mean arterial blood pressure (MBP), as measured by carotid artery cannulation, was stable in the sham-operated rats at the different time-points after surgery (Table I). MBP was significantly increased at 1 week after surgery and continued to increase. 
A

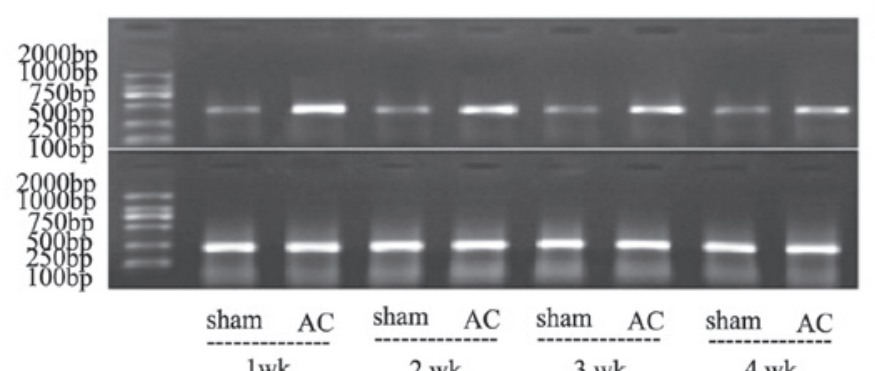

$\mathrm{C}$

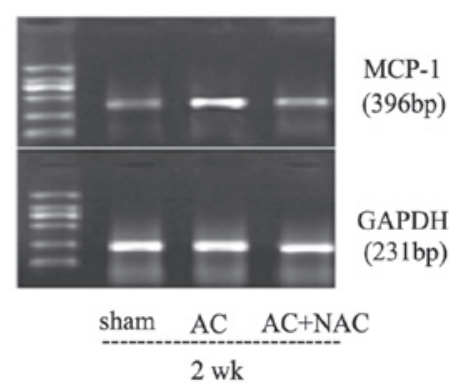

B

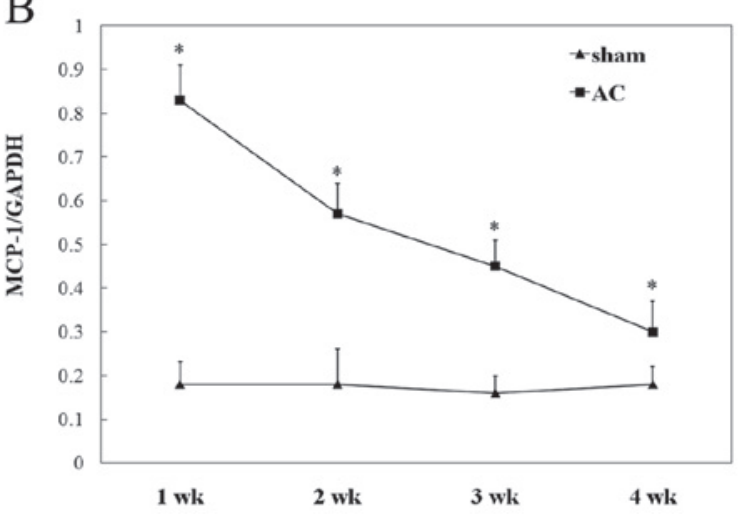

$\mathrm{D}_{0.7}$

$4 \mathrm{wk}$

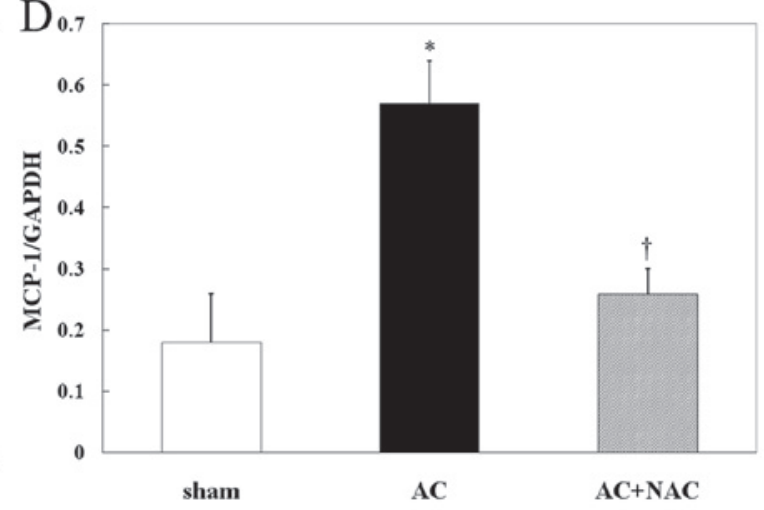

Figure 2. Changes in MCP-1 mRNA levels in pressure-overloaded rat hearts and the effects of NAC administration. (A) Representative images of electrophoresis of RT-PCR products for MCP-1 and GAPDH from the sham-operated and AC groups at different time-points. (B) Densitometric analysis of the data in (A) showed the temporal characteristics of MCP-1 expression in pressure-overloaded rat hearts. (C) Representative images from sham-operated, AC and NAC groups at 2 weeks. (D) Densitometric analysis of the data in (C). All the data were derived from 4 hearts for each group. " $\mathrm{P}<0.01$ vs. age-matched sham-operated group; ' $\mathrm{P}<0.01$ vs. age-matched $\mathrm{AC}$ group. MCP-1, monocyte chemoattractant protein-1; AC, aortic coarctation; NAC, N-acetylcysteine; wk, week.

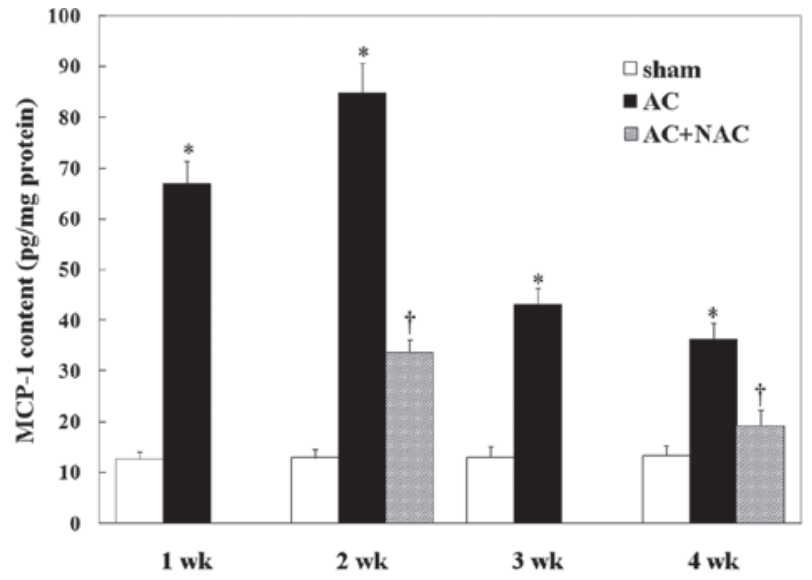

Figure 3. Changes in MCP-1 protein levels in pressure-overloaded rat hearts and effects of NAC administration. ${ }^{*} \mathrm{P}<0.01 \mathrm{vs}$. age-matched sham-operated group; ${ }^{\dagger} \mathrm{P}<0.01$ vs. age-matched AC group. $\mathrm{n}=8$. MCP-1, monocyte chemoattractant protein-1; AC, aortic coarctation; NAC, N-acetylcysteine; wk, week.

While there was no significant difference in body weight in the rats between the age-matched $\mathrm{AC}, \mathrm{AC}+\mathrm{NAC}$ and shamoperated groups, pressure overload induced a significant increase in LV weight, the ratio of $\mathrm{LV}$ weight to body weight, and cardiac fibrosis at 2 weeks, suggesting the presence of cardiac hypertrophy and fibrosis in the rats with AC. However, perivascular fibrosis was increased at 1 week, preceding the change in cardiac hypertrophy and fibrosis. All the parameters further increased with the persistence of pressure overload. NAC administration for 2 or 4 weeks blunted the morpho- logical changes, but had no significant effect on blood pressure (Table I).

Pressure-overload induced changes in MCP-1 mRNA and protein levels in myocardium and effects of NAC administration. MCP-1 mRNA levels in the myocardium of rats with $\mathrm{AC}$, as detected by RT-PCR, increased markedly and promptly reached the peak at 1 week (Fig. 2). Then, the MCP-1 mRNA levels declined at 2, 3 and 4 weeks but were still at a higher level than those of the sham-operated rats. There was no difference among the MCP-1 mRNA levels in the sham-operated group at the different time-points. Compared with the rats with AC, NAC administration for 2 weeks significantly inhibited the increase in MCP-1 mRNA levels $(0.26 \pm 0.04$ vs. 0.57 \pm 0.07 ; $\mathrm{P}<0.01)$. The protein levels of MCP-1 in the hearts of rats with $\mathrm{AC}$, as determined by ELISA, were elevated significantly at 1 week $(66.9 \pm 4.5$ vs. $12.7 \pm 1.3 \mathrm{pg} / \mathrm{mg}$ protein in age-matched sham-operated rats; $\mathrm{P}<0.01)$, peaked at 2 weeks $(84.8 \pm 5.9$ vs. $12.9 \pm 1.7 \mathrm{pg} / \mathrm{mg}$ protein; $\mathrm{P}<0.01)$ and declined steadily $(43.1 \pm 3.1$ vs. $13.0 \pm 2.1 \mathrm{pg} / \mathrm{mg}$ protein at 3 weeks; $36.2 \pm 3.2 \mathrm{vs} .13 .3 \pm 1.9 \mathrm{pg} /$ $\mathrm{mg}$ protein at 4 weeks; both $\mathrm{P}<0.01$ ). NAC administration for 2 or 4 weeks, markedly attenuated the increase in MCP-1 protein levels in the AC group $(33.7 \pm 2.4 \mathrm{pg} / \mathrm{mg}$ protein at 2 weeks; $19.35 \pm 2.82 \mathrm{pg} / \mathrm{mg}$ protein at 4 weeks; both $\mathrm{P}<0.01$ ) (Fig. 3).

Pressure overload-induced MAPK activation in myocardium and effects of NAC administration. The activation of different MAPK isoforms was determined by western blot analysis (Fig. 4). In the rats with AC at 2 weeks after surgery, the activity of ERK and JNK increased by 53 and 40\%, respectively 

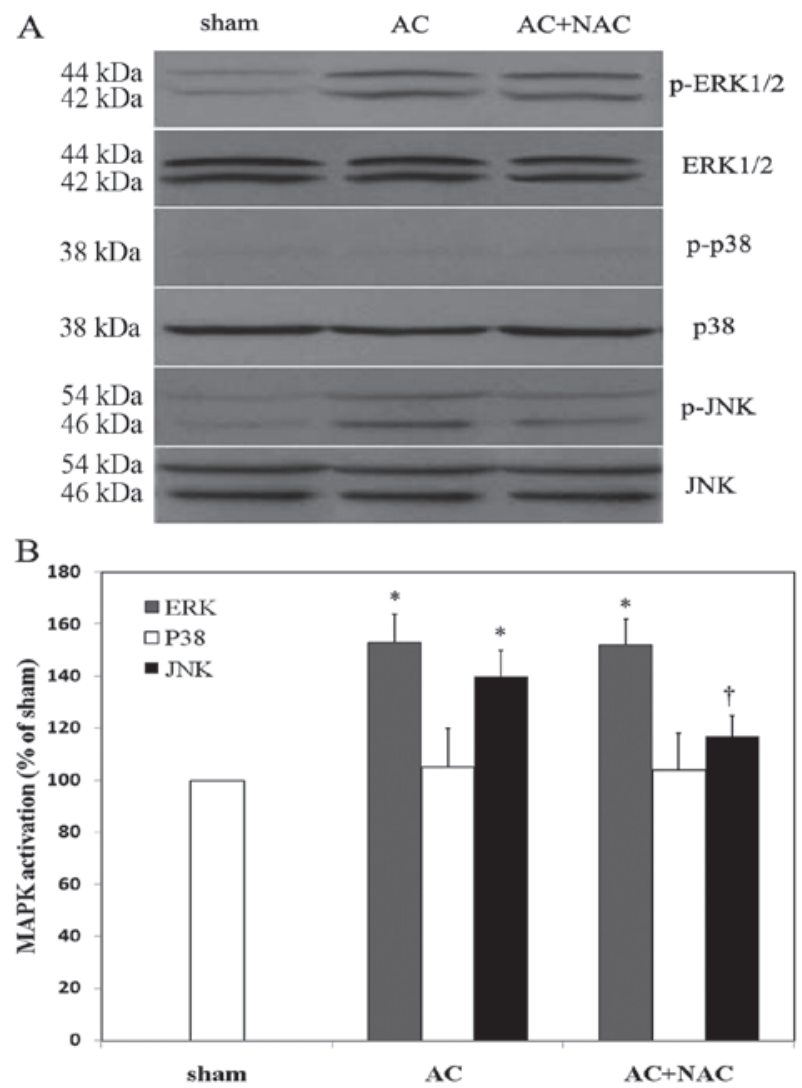

Figure 4. Activation of different MAPK isoforms in the pressure-overloaded rat hearts and effects of NAC administration. The activation of MAPK was reflected as the ratio of the phosphorylation level to the total amount of MAPK isoforms. (A) Representative immunoblot showing the activation of ERK, p38 and JNK in myocardium from sham-operated, $\mathrm{AC}$ and $\mathrm{AC}+\mathrm{NAC}$ groups at 2 weeks. (B) Densitometric analysis of the activation of ERK, p38 and JNK. Results were normalized by a random setting of the densitometer of shamoperated group sample as $100 \%$. All the data were derived from 4 hearts for each group. " $\mathrm{P}<0.01$ vs. age-matched sham-operated group; ${ }^{\circ} \mathrm{P}<0.01$ vs. agematched AC group.

(both $\mathrm{P}<0.01$ ). The activity of $\mathrm{p} 38$ did not change between the sham-operated and AC groups. While NAC administration for 2 weeks inhibited the activation of JNK (117 \pm 8 vs. $140 \pm 10 \%$; $\mathrm{P}<0.01)$, NAC had no effect on the activity of ERK $(150 \pm 10 \mathrm{vs}$. $153 \pm 11 \%$; $>0.05)$.

\section{Discussion}

The major findings of the present study are that i) NADPHdependent ROS generation increased significantly in the myocardium of pressure-overloaded rat hearts; ii) the increase of ROS was paralleled by the expression of MCP-1 and LV remodeling; iii) the administration of NAC, which is a ROS scavenger, reduced the ROS levels in the pressure-overloaded rat myocardia, and ameliorated the cardiac structural changes; iv) ERK and JNK, but not p38, were activated in the myocardium of pressure-overloaded rat hearts, and NAC administration inhibited the activation of JNK, but not ERK. These results suggest that the upregulation of $\mathrm{MCP}-1$ proteins in pressure-overloaded rat hearts is mediated, at least in part, by enhanced ROS production; JNK may be involved in the downstream signaling pathway.
Compelling evidence in various hypertensive models has suggested a pivotal role of inflammation in the development of hypertension, particularly the development of cardiac fibrosis $(2,3)$. It has been reported that inflammation directly contributes to reactive and reparative fibrosis, with inflammatory cells secreting profibrogenic factors, such as TGF- $\beta$ and promoting the phenotypic transformation of cardiac fibroblasts to myofibroblasts, which adds to the collagen generation (5). Chemokines play a pivotal role in the infiltration of inflammatory cells, and MCP-1 is one of the major chemokines (3). Consistent with previous reports (5), the present study demonstrates an increased MCP-1 expression in the myocardium of pressure-overloaded rat hearts, preceding cardiac remodeling. It has been shown that, in hypertensive animal models, the administration of MCP-1 neutralizing antibody inhibits the inflammatory reaction and cardiac fibrosis $(4,5)$. Thus, modulating the expression/function of MCP-1 proteins may represent a potential therapeutic tool to control cardiac fibrosis in hypertensive patients. Accordingly, further investigations to explore the mechanisms underlying the increased expression of MCP-1 and the initiation of inflammation in the pressure-overloaded myocardium are necessary.

ROS are now recognized as an important second messenger in cellular signaling transduction (6), and have been shown to modulate the expression of many genes that are related to cell apoptosis, proliferation and inflammation $(6,15)$. ROS production is regulated by many physiological and pathological stimuli. In hypertensive patients and animals, ROS generation is enhanced directly by shear stress (16), and indirectly via the receptor activation of angiotensin II, endothelin and other humoral factors (17). NADPH oxidase is one of the major sources of ROS generation $(8,18)$, and NADPH oxidase subunit expression and activities are increased in hypertensive models $(8,19)$. Consistent with previous studies, the present study demonstrated that NADPH-dependent ROS generation was significantly increased at 1 week after the initiation of $\mathrm{AC}$, which was concomitant with the expression of MCP-1. In order to further investigate the role of ROS in early inflammation, NAC was used as a ROS scavenger (20). In this study, NAC significantly reduced ROS levels, and inhibited MCP-1 expression and the recruitment of inflammatory cells. NAC administration also attenuated cardiac remodeling in the pressure-overloaded rat hearts. However, blood pressure was not affected by NAC administration, suggesting that the inflammatory reaction is not pressure-dependent in cardiac remodeling. All these results suggest that increased NADPH-dependent ROS generation may mediate the expression of MCP-1 and the subsequent inflammation in pressure-overloaded rat hearts.

Although the correlation between ROS and MCP-1 gene transcription has been identified in both rat myocardium (present study), and cultured human aortic endothelial cells $(11,21)$, little is known about the intermediate signaling molecules. The effects of ROS on gene transcription were found to be mainly mediated by the activation of certain kinases and transcription factors. The MAPK signaling pathway is critical in the development of cardiac hypertrophy (22), and the role of MAPKs (in particular p38 and JNK isoforms) in inflammation have been suggested in previous studies $(23,24)$. The present study showed that ERK and JNK were activated in pressure-overloaded rat hearts at 2 weeks, at which stage MCP-1 expression and macrophage 
filtration were at higher levels. NAC administration inhibited JNK activation but not that of ERK, suggesting that the activation of JNK, but not ERK, may be mediated by ROS. Increasing evidence has indicated that MAPK isoforms can be activated differently and exert different biological functions. ERK tends to be involved in cell proliferation and hypertrophy, while p38 and JNK are more likely to be implicated in inflammation and cell apoptosis (25). p38 activation was not found in this study, which is consistent with a previous study by Li et al (8). In the same model, they found that p38 was activated at later stage as compared with ERK and JNK, and suggest that $\mathrm{p} 38$ may play an important role during the transition from heart hypertrophy to failure. After JNK is activated by oxidative stress or other types of stress, JNK-mediated phosphorylation enhances the ability of c-Jun, a component of the AP-1 transcription factor, to activate gene transcription (26). The JNK activation leads to the induction of AP-1-dependent target genes involved in inflammation (24). In cultured rat microglial cells and human corneal fibroblasts, it has been shown that JNK activation mediates MCP-1 expression $(27,28)$. All these data suggest the association of JNK with MCP-1 expression. However, the correlation between MCP-1 gene expression and the ROS-dependent JNK activation in pressure-overloaded rat hearts needs to be further studied.

In conclusion, the present study suggests that ROS mediates the increased expression of MCP-1 in a pressure-overloaded rat heart model, and that JNK is likely involved in the signaling pathway. This study provides rationale for using antioxidants to prevent and control inflammation and ensuing cardiac remodeling in the context of hypertension.

\section{References}

1. Buja LM and Vela D: Cardiomyocytes death and renewal in the normal and diseased heart. Cardiovasc Pathol 17: 349-374, 2008.

2. Roselló-Lletí E, Rivera M, Martínez-Dolz L, et al: Inflammatory activation and left ventricular mass in essential hypertension. Am J Hypertens 22: 444-450, 2009.

3. Niu J and Kolattukudy PE: Role of MCP-1 in cardiovascular disease: molecular mechanisms and clinical implications. Clin Sci (Lond) 117: 95-109, 2009.

4. Koyanagi M, Egashira K, Kitamoto S, et al: Role of monocyte chemoattractant protein-1 in cardiovascular remodeling induced by chronic blockade of Nitric oxide synthesis. Circulation 102: 2243-2248, 2000.

5. Kuwahara F, Kai H, Tokuda K, et al: Hypertensive myocardial fibrosis and diastolic dysfunction: another model of inflammation. Hypertension 43: 739-745, 2004.

6. Thannickal VJ and Fanburg BL: Reactive oxygen species in cell signaling. Am J Physiol Lung Cell Mol Physiol 279: L1005-L1028, 2000.

7. Paravicini YM and Touyz RM: Redox signaling in hypertension. Cardiovasc Res 71: 247-258, 2006.

8. Li JM, Gall NP, Grieve DJ, Chen M and Shah AM: Activation of NADPH oxidase during progression of cardiac hypertrophy to failure. Hypertension 40 477-484, 2002.

9. Tsujimoto I, Hikoso S, Yamaguchi O, et al: The antioxidant edaravone attenuates pressure overload-induced left ventricular hypertrophy. Clin Invest 115: 1221-1231, 2005.
10. Cakir Y and Ballinger SW: Reactive species-mediated regulation of cell signaling and the cell cycle: the role of MAPK. Antioxid Redox Signal 7: 726-740, 2005 .

11. Wung BS, Cheng JJ, Hsieh HJ, Shyy YJ and Wang DL: Cyclic strain-induced monocyte chemotactic protein-1 gene expression in endothelial cells involves reactive oxygen species activation of activator protein 1. Circ Res 81: 1-7, 1997.

12. Zhang D, Gaussin V, Taffet GE, et al: TAK1 is activated in the myocardium after pressure overload and is sufficient to provoke heart failure in transgenic mice. Nat Med 6: 556-563, 2000.

13. Sun Y, Ratajiska A and Weber KT: Inhibition of angiotensinconverting enzyme and attenuation of myocardial fibrosis by lisinopril in rats receiving angiotensin II. J Lab Clin Med 126: 95-101, 1995

14. Li JM, Mullen AM, Yun S, et al: Essential role of the NADPH oxidase subunit $\mathrm{p} 47$ (phox) in endothelial cell superoxide production in response to phorbol ester and tumor necrosis factor- $\alpha$. Circ Res 90: 143-150, 2002.

15. Lavrovsky Y, Chatterjee B, Clark RA and Roy AK: Role of redox-regulated transcription factors in inflammation, aging and age-related diseases. Exp Gerontol 35: 521-532, 2000.

16. Touyz RM and Schiffrin EL: Reactive oxygen species in vascular biology: implications in hypertension. Histochem Cell Biol 122: 339-352, 2004.

17. Pollock DM: Endothelin, angiotensin, and oxidative stress in hypertension. Hypertension 45: 477-480, 2005.

18. Zalba G, Beaumont FJ, San Jose G, et al: Vascular NADH/ $\mathrm{NAD}(\mathrm{P}) \mathrm{H}$ oxidase is involved in enhanced superoxide production in spontaneously hypertensive rats. Hypertension 35: 1055-1061, 2000.

19. Matsuno K, Yamada H, Iwata K, et al: Nox1 is involved in angiotensin II-mediated hypertension: a study in Nox1-deficient mice. Circulation 112: 2677-2685, 2005.

20. Zafarullah M, Li WQ, Sylvester J and Ahmad M: Molecular mechanisms of $\mathrm{N}$-acetylcysteine actions. Cell Mol Life Sci 60: 6-20, 2003

21. Chen XL, Zhang Q, Zhao R and Medford RM: Superoxide, $\mathrm{H}_{2} \mathrm{O}_{2}$, and iron are required for TNF-alpha-induced MCP-1 gene expression in endothelial cells: role of Racl and NADPH oxidase. Am J Physiol Heart Circ Physiol 286: H1001-H1007, 2004.

22. Takeishi Y, Huang Q, Abe J, et al: Src and multiple MAP kinase activation in cardiac hypertrophy and congestive heart failure under chronic pressure-overload: comparison with acute mechanical stretch. J Mol Cell Cardiol 33: 1637-1648, 2003.

23. Li M, Georgakopoulos D, Lu G, et al: p38 MAP kinase mediates inflammatory cytokine induction in cardiomyocytes and extracellular matrix remodeling in heart. Circulation 111: 2494-2502, 2005.

24. Karin M and Gallagher E: From JNK to pay dirt: jun kinases, their biochemistry, physiology and clinical importance. IUBMB Life 57: 283-295, 2005.

25. McMullen ME, Bryant PW, Glembotski CC, Vincent PA and Pumiglia KM: Activation of p38 has opposing effects on the proliferation and migration of endothelial cells. J Biol Chem 280: 20995-21003, 2005.

26. Mandal M, Olson DJ, Sharma T, Vadlamudi RK and Kumar R: Butyric acid induces apoptosis by upregulating Bax expression via stimulation of the c-Jun N-terminal kinase/activation protein-1 pathway in human colon cancer cells. Gastroenterology 120: 71-78, 2001 .

27. Waetzig V, Czeloth K, Hidding U, et al: c-Jun N-terminal kinases (JNKs) mediate pro-inflammatory actions of microglia. Glia 50: 235-246, 2005

28. Xiao J and Chodosh J: JNK regulates MCP-1 expression in adenovirus type 19-infected human corneal fibroblasts. Invest Ophthalmol Vis Sci 46: 3777-3782, 2005. 